This item was submitted to Loughborough's Research Repository by the author.

Items in Figshare are protected by copyright, with all rights reserved, unless otherwise indicated.

\title{
Managing construction health and safety: migrant workers and communicating safety messages
}

PLEASE CITE THE PUBLISHED VERSION

http://dx.doi.org/10.1016/j.ssci.2007.06.026

PUBLISHER

(C) Elsevier

VERSION

AM (Accepted Manuscript)

LICENCE

CC BY-NC-ND 4.0

REPOSITORY RECORD

Bust, Phillip D., Alistair G.F. Gibb, and Sarah Pink. 2019. "Managing Construction Health and Safety: Migrant Workers and Communicating Safety Messages". figshare. https://hdl.handle.net/2134/9234. 
This item was submitted to Loughborough's Institutional Repository (https://dspace.lboro.ac.uk/) by the author and is made available under the following Creative Commons Licence conditions.

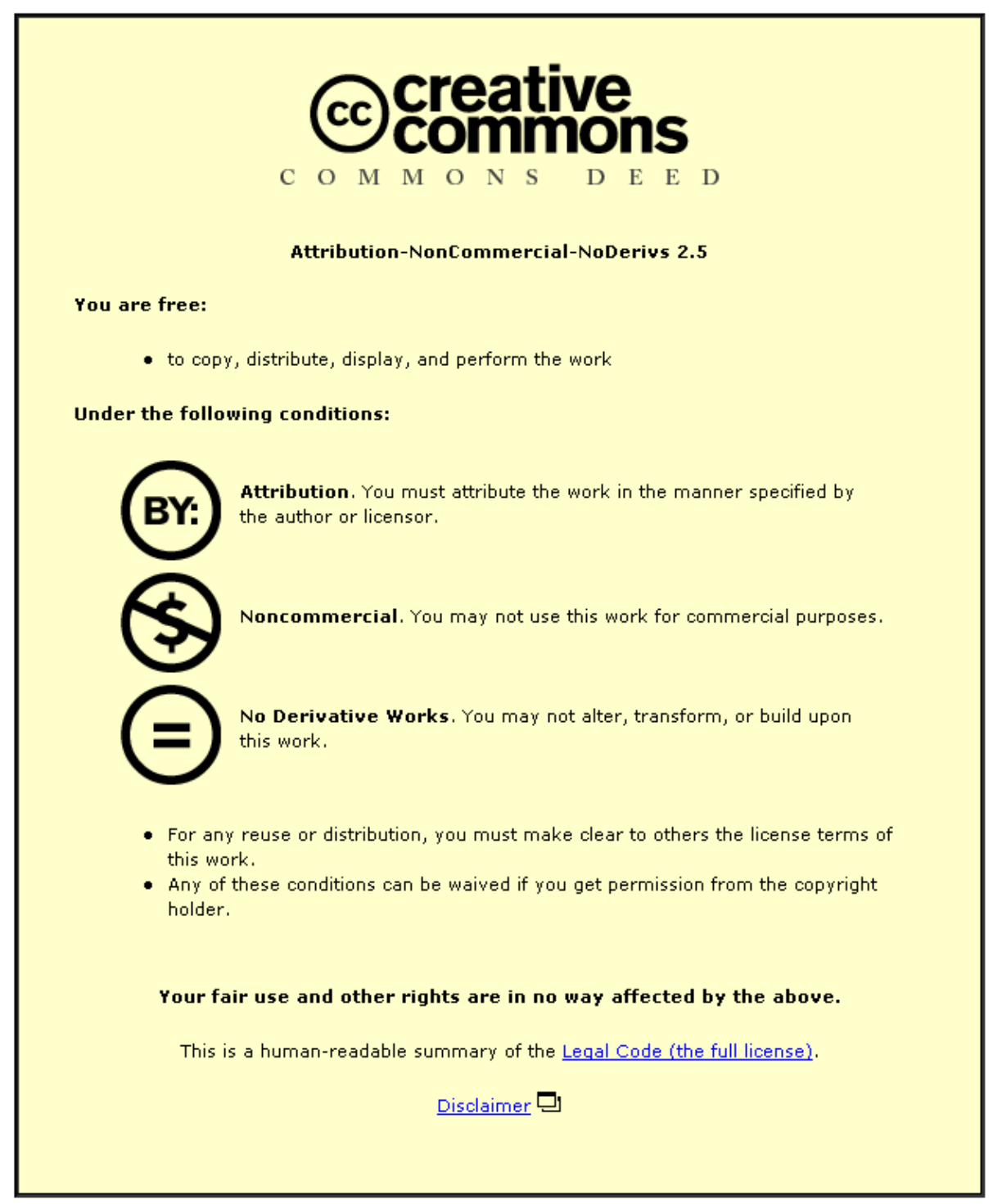

For the full text of this licence, please go to: http://creativecommons.org/licenses/by-nc-nd/2.5/ 


\title{
Managing Construction Health and Safety: Migrant Workers and Communicating Safety Messages
}

\author{
Philip D Bust, Alistair G F Gibb and Sarah Pink* \\ Department Civil and Building Engineering, Loughborough University, \\ Leicestershire LE11 3TU, UK \\ *Department of Social Sciences Loughborough University, \\ Leicestershire LE11 3TU, UK \\ Correspond to: p.d.bust@lboro.ac.uk
}

\begin{abstract}
The economic prosperity of individual countries around the world has fuelled the transportation of migrant workers for centuries. The phenomenon of globalisation and with it cheaper and quicker forms of international travel has transformed the nature of migrant worker involvement in construction projects. For example, Irish 'navies' have traditionally made up a large percentage of the UK construction workforce. However, political changes in the neighbouring Republic of Ireland leading to an economic boom have kept native workers at home. This gap in the UK workforce has coincided with an expansion of the European Union and there has been an influx of Polish, Lithuanian and other A8 ascension countries' nationals.

The change, over a relatively short period of time, less than 10 years, has put pressure on the management of health and safety at a time when the UK construction industry was progressing from relative successes in tackling safety issues to dealing with the health of construction workers. The challenge of converting the health and safety systems to accommodate a multi national/ cultural workforce is being addressed using initiatives such as, translation of health and safety materials, use of interpreters and an increased use of visual methods for communicating health and safety messages. There is little scientific evidence to support the effectiveness of these initiatives and investigations into these methods and the affects of the migrant workforce on health and safety are proposed.
\end{abstract}




\section{INTRODUCTION}

\subsection{Globalisation - and Global Safety Project}

Globalisation is an inescapable fact. It is no longer possible for governments to legislate in isolation because changes that once only affected their own population and possible their nearest neighbours now have more far reaching consequences. This is in some part possible due to cheaper methods of travel and instant worldwide communication through the internet. Workers are able to find out about work through internet agencies and travel to different countries at a relatively low cost.

Together with the growing international activity in construction there has been an increasing awareness of the importance of better understanding cross-cultural management (Torrance, 2004). As the workforce may be drawn from many different countries, use many languages and have a variety of cultural backgrounds. Culture frames the ways in which we express ourselves (Langford, 2000) and how we interpret the actions of others. We can express ourselves in a number of ways

- Verbally - What we say

- Paraverbally - How we say it

- Nonverbal - body language

Through action - by doing things in particular ways (consciously or unconsciously)

People from different nationalities and ethnic groups express themselves and understand the behaviours of others in different ways, which are informed by specific sets of cultural knowledge and conventions. Thus cross-cultural misunderstandings occur which can lead to health and safety problems. Therefore a new approach to the management of health and safety is required.

In the UK and abroad this issue is being dealt with in similar ways. Translation of safety information, use of interpreters and a variety of visual methods to communicate essential health and safety information. It is essential that the effectiveness of these methods is assessed as well as the full impact of migrant workers on health and safety in construction.

Loughborough University, supported by the European Construction Institute (ECI), carried out research visiting projects in Africa, Asia, India, the Middle East and Eastern Europe to observe the health and safety measures employed and interview management staff. The visits together with a series of interviews and focus groups in the UK and mainland Europe were used to produce a guidance manual (Bust and Gibb, 2006). After the completion of that project crossdepartmental (Social Sciences and Civil and Building Engineering) discussions at the University identified areas for further investigation. First, it was thought that the work in developing countries also raised questions about construction in the UK where there has been an increase in the numbers of migrant workers being employed. Second, that this situation called for an assessment of the increasing variety of visual methods being used to communicate about health and safety on and about construction sites was necessary.

\subsection{Migrant Workforces}

The use of migrant workers in construction is a worldwide phenomenon and it is common practice in the UK. A structurally embedded reliance on cheap and 'flexible' sources of regularly and irregularly employed migrant workers has 
always been a key feature of the UK construction sector (Balch and Geddes 2003).

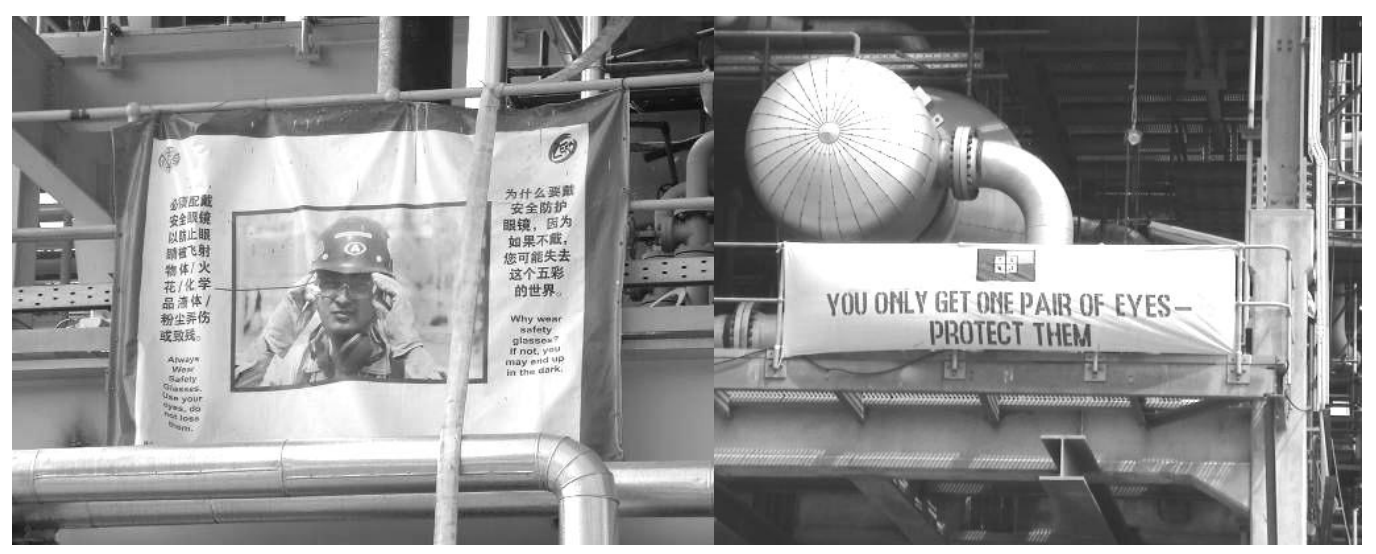

Figure $1 \mathrm{H} \& S$ Banner in China

Figure 2 H\&S Banner in Nigeria

However, a combination of events (expansion of the European Union, a buoyant UK economy and an absence of the traditional Irish migrant workforce due to a boom in the Republic) has led to an increase in the numbers of foreign nationals. This has been recognised by the Construction Industry Training Board (CITB) and the Construction Confederation in the UK. They have worked together to produce the 'A Simple Guide to Clearer Communication' publication outlining methods for clearer verbal communication, recommendations for notices and examples of good and bad communication. Included in this is the recommended use of pictures on signs to convey safety information.

As the UK construction industry adjusts to a changing workforce it needs to be aware of the implications and learn from other countries. Research on construction safety in Kuwait reported that there was an extensive use of foreign labour; that different labour cultures and traditions reflect on human relations, different work habits, and communication problems; and the workers were emotionally vulnerable and preoccupied with their problems. All of these factors can affect the concentration and attention of the worker and may contribute to mistakes. (Kartam et al 2000)

Although there may be many cultural and religious aspects that need to be understood the obvious change is having to deal with a workforce with a growing communication barrier. The inability to immediately communicate via the spoken word on construction sites represents one of the major barriers to successful management of health and safety. From our investigations on the Global Safety project we learnt that when multinational consortia work alongside workforces derived from many countries, the opportunity for the message to be lost in translation is increased. When looking at factors contributing to construction accidents it was reported (Haslam et al 2005) that worker participation in managing safety was important to generate ideas and to build ownership and responsibility. This will be difficult to achieve if the number of different languages spoken on construction sites continues to increase.

Acting on responses to the HSE's discussion document 'Revitalising Health and Safety in Construction' (HSE 2003) it was said that in order to engage the workforce the HSE had to develop proposals for tackling language and literacy issues. This is now taxing health and safety managers throughout the UK. 


\subsection{Communication - use of images}

One of the earliest uses of graphics to improve communication of warning messages was by the US Workmen's Compensation Service Bureau which was a pictorial representation of approved personal protective equipment required to be worn by workers. In the mid 1920's the idea to use posters to inform worker accident prevention measures was introduced by safety engineers. This was based on the premise that an informed worker is more likely to perform his/her job at relatively low risk. It was about this time that "Safety First" posters were introduced in workplaces in the UK.

In order for us to understand the use of pictures to convey information we are required to look beyond the construction industry. Oller et al (1999) from an advertising perspective states that to capture attention, nothing works better than picture, and moving pictures are better than still pictures. Leiner et al (2004) confirmed the statement through research on communication of polio vaccination when they found that using marketing and advertising techniques in animated cartoons can improve knowledge among parents/caretakers regarding polio vaccination. Their findings also suggested that processing the message in a colourful and more interesting format transmited the message more effectively.

In another study Racicot and Wogalter (1995) found that behavioural change induced by the video warning sign is robust over time. Moriyama et al (2004) found that non-animated cartoons improve communication between health and care providers and patients. Delp and Jones (1996) concluded that cartoon illustrations improved patient compliance with early discharge release instructions.

The Health and Safety at Work Act states that - "For employees with little or no understanding of English, or who cannot read English, employers may need to make special arrangements. These could include providing translation, using interpreters, or replacing written notices with clearly understood symbols or diagrams."

An increasingly popular method of conveying health and safety messages to a wide multilingual audience is by (audio)visual means. Traditionally, training material in health and safety has been enhanced by the use of cartoons in manuals and graphic videos showing accidents to help get the message across to usually unresponsive groups of workers. Digital technology facilitates the capturing of site-related images, quickly transferring these into posters or other media to communicate the message in a very relevant way. Thus visual means of communicating health and safety information is being used and quite possibly more so with the increase in foreign nationals in construction. Yet, while safety managers need to know how effective these (audio)visual communications are, there does not appear to be any sign that the methods have been evaluated. Indeed, research about communication and second language speakers in the construction industry (Schellekens and smith 2004) found that supervisors were not aware that the 1996 EC Safety Signs Directive in fact requires employers to explain unfamiliar signs to their employees and to tell them what to do when they see a safety sign; word-signs were found on most sites and one site used only these.

\subsection{How do visual representations of safety information communicate?}


The results of the Global Safety project demonstrated an increasing use of (audio) visual representations in multiple media and formats for communication about health and safety issues on construction sites. Yet there is a lack of knowledge about how these texts are interpreted by construction workers. We do not know how they engage with the content of the text, the extent to and ways in which (audio)visual health and safety texts and installations can influence work practices, or how the cultural and personal knowledge about health and safety that construction workers bring on site with them intersects with the scientifically informed health and safety knowledge represented in these texts. There is a clear need for further research that will address these questions. Indeed the increased use of visual images, often following the increasing accessibility of digital technologies, is not unique to construction sites. This has been noted across a range of academic and applied disciplines, where researchers are recognising the importance of understanding how the (often multimedia) narratives of new (audio)visual texts and installations communicate, are understood and are used by their target audiences. Perhaps one of the most striking examples can be seen in the recent literature of the nascent sub-discipline of visual legal studies, which, amongst other things, lends itself to deconstructing how visual images are now being used to create powerfully persuasive narratives in court cases (Sherwin, Feigenson and Spiesel 2007 forthcoming). Therefore the idea we discuss here run parallel to initiatives being developed in other applied disciplines where the importance of attending to the complexities of (audio)visual communication in multicultural contexts has already been recognised.
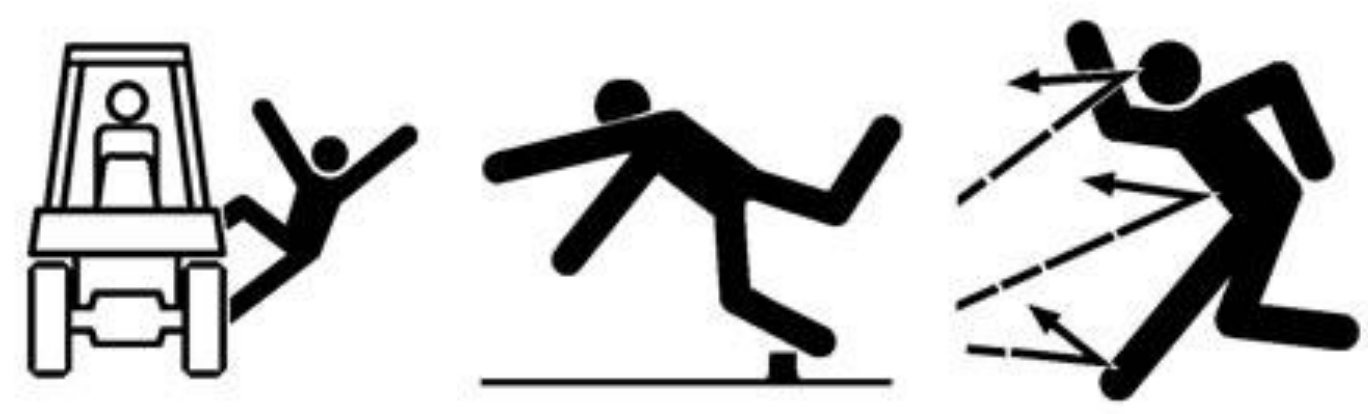

Figure 3 Examples from the Association of Equipment Manufacturers Pictogram Database

To respond to the need for further research into the role of (audio)visual communications on construction sites, a multidisciplinary team at Loughborough University has been drawn up to propose a way to proceed using the Civil and Building Engineering department's experience with the Global Safety project and the visual research and analysis methods used in the Social Sciences department. This section describes the proposed development of such research, using visual methods that originate in the subdiscipline of applied visual anthropology. This body of work is of particular relevance here for several reasons.

I. One of our concerns is to examine how construction workers use their own experience-based knowledge (which will be partly personal/biographical and partly cultural) in two ways: first to understand the related concepts of 'health' and 'safety'; and second to interpret (audio)visual Health and Safety texts. In doing so we believe that we need to understand constructions workers' approaches to health and safety as well in their everyday work practices, as being personal/individual but also shaped by their culture. This requires a comparative analysis, by which we will examine how construction workers from different cultures and countries of origin use different experience-based cultural understandings to ensure that their working 
environments are (on their terms although perhaps not on the terms of health and safety regulations) 'safe' and ensure their own 'health'.

II. We wish to understanding the potentials and limitations of the current uses of (audio)visual media to communicate about health and safety to construction workers of increasingly diverse cultures and nationalities. In doing so we take some insights from academics working in the subdiscipline of visual anthropology who have grappled with similar questions about how to communicate about the experiences of one group of people's to another (different) group for years. Applied visual anthropologists confront this issue both when they use (audio)visual representations with the intention of increasing mutual understanding between one group and another. It has been suggested that documentary film can evoke empathetic responses and a sense of actual bodily experience of persons represented to the audience (e.g. Taylor 1998, MacDougall 1998). Although it is impossible to actually understand what it really feels like to be someone else the directness of visual communication and its tendency to invite its viewers to imagine what other people might be experiencing is significant. Because visual images encourage viewers to empathise with the physical and emotional experiences of those they represent, they have significant potential for the communication of information about the possible bodily consequences of certain actions (including danger, pain and injury, and as such health and safety). However, because, as indicated by our existing research (below/above) people from different cultures have different understandings of health and safety, the communication process becomes more complex. It seems to us that research is now required to understand the potentials and limitations of the current uses of (audio)visual media to communicate about health and safety to construction workers of increasingly diverse cultures and nationalities. We need to be aware of how cultural differences will lead individuals from different cultures to interpret the possible physical and emotion consequences of particular actions represented (audio)visually.

If (audio)visual texts and exhibits are to communicate efficiently about health and safety on construction sites these factors need to be accounted for in their design. In the next sections we outline a series of research exercises we have undertaken to date which provide context for the qualitative approach we advocate. Then we outline how we propose to develop our research further, referring where applicable to a pilot study carried out in September 2006.

\section{Global Safety Research Project and Pilot Studies}

The Global Safety project revealed migrant workforces as a key factor in the management of health safety and visual methods of communicating health and safety messages as a widely used solution.

It was decided that these areas needed further investigation and a series of pilot studies were carried out to gather data.

\subsection{Global Safety Project}

The Constructing Global Health and Safety project was carried out during 200405 with the following work being carried out:

- Visits - Countries visited were China, Hong Kong, Thailand, Nigeria, Poland, South Africa, India, United Arab Emirates and Qatar. Whilst some of these countries are not recognised as being developing countries the workers on projects in these countries are usually predominately from developing countries. 
- Interviews - Informal interviews were carried out with project members during the visits and with European Construction Institute members, in their offices, to gather information on the problems they had encountered whilst working in developing countries and, wherever possible, to record any solutions they had discovered.

- Focus groups - Three focus groups were held to examine some of the issues raised in the workshops and that became evident from the visits. Topics included the use of construction equipment and the characteristics of developing countries and their workers.

- Questionnaire - there were 87 questionnaires completed. The average age of the respondents was 48 . They had an average work experience of $11 \frac{1}{2}$ years working mainly as health, safety and environmental managers. The number of countries they had worked in was 44.

From the visits it was noted that varied and sometimes novel visual methods were being used to communicate health and safety information. Difficulties communicating either directly with a foreign worker or indirectly through an interpreter were cited during the interviews. In the focus groups, equipment designers said that they had to account for language issues when applying warning labels.

\subsection{ECI Workshop - migrant workers}

A workshop was conducted as part of the European Construction Institute's Safety Health and Environment Working Group to discuss the impact of migrant workers on the management of health and safety on engineering and construction projects.

Two main questions were put to the workshop participants and a summary of their answers can be seen below.

Question 1 - Are migrant workers more of a problem on construction sites than native workers?

- The good migrant workers and the bad ones tended to cancel each other out.

- Language was felt to be the big issue and the number of languages being used was seen as even more of a problem.

- Migrant workers were considered more likely to do something dangerous than native workers.

- In Spain, where migrant workers are mainly from North Africa, large cultural differences were perceived.

- Fasting during the day in Ramadan had to be taken into account as it could affect the worker's physical condition.

- There was a certain amount of stereotyping such as - migrant workers being more likely to sell their construction equipment and that "they all look the same".

Question 2 - If migrant workers affect the management of health and safety on construction sites, how can this be dealt with?

- It was suggested that pictures should be used and that the consequences of inappropriate actions should be shown.

- Participants felt that translation of health and safety information was not always successful. 
A meeting was held with the Health and Safety management team (4No) for the Channel Tunnel Rail Link (CTRL) project to discuss what effect the migrant workforce used on the project had had on the management of health and safety and what means they had adopted to cope with this.

A list of the health and safety managers' comments is shown below.

- A filter system was used with security checks which included criminal records and National Insurance numbers.

- Efforts were made to keep people in their own groups and ensure that they were familiar and understood the main warnings.

- The main contractor carried out the inductions and the sub-contractors sent workers to them. Workers with difficulties were given a 'one on one' induction. Any shortfalls in the workers were then reported back to the sub-contractors.

- All workers were required to have a basic understanding of English.

- CTRL demanded a high level of commitment to health and safety. Subcontactors were not all on board early in the contract but all became committed with time.

- Polish workers installed the overhead lines. However these were experts in this field and travelled from country to country carrying out this type of work.

- The team had started to look at translating posters into 19 different languages but decided this wouldn't work.

- $\quad$ Speaking to French workers who understood some English was not working until a French translator was used who stood with them and then they understood.

\subsection{Telephone Survey - migrant workers}

A telephone survey was carried out in order to gauge the extent of the influence of migrant workers on health and safety management in construction. A small sample (10No.) of health and safety manager and directors were contacted but this had a large geographical spread, covering the North, West, Midlands, London and the South. All those spoken to had a role in health and safety (Director, Manager, Consultant) and the organisations were varied in nature (Local Authority, national and local building, civil and road contractors)

The questions asked were derived from the previous workshop and interviews and steering group discussions. These are shown in table 1 below.

Table 1

Telephone Survey Questions - Migrant Workers

1 Approximately what percentage of your construction site workforce are foreign nationals

2 In which construction trades do you use migrant workers mostly

3 How do you ensure that these workers understand their health and safety responsibilities

$4 \quad$ What, would you say, are the consequences to the management of health and safety in construction of employing migrant workers

5 In the next ten years do you think the construction industry will use more, less or the same amount of migrant workers

The results of the telephone survey are shown below. 
Question 1 - Approximately what percentage of your construction site workforce are foreign nationals.

The average response to this question was approximately $10 \%$ with one contractor stating that they had around $40 \%$ migrant workers in their workforce (which rose to $50 \%$ when considering only unskilled workers) and another that had none.

Question 2 - In which construction trades do you use migrant workers mostly.

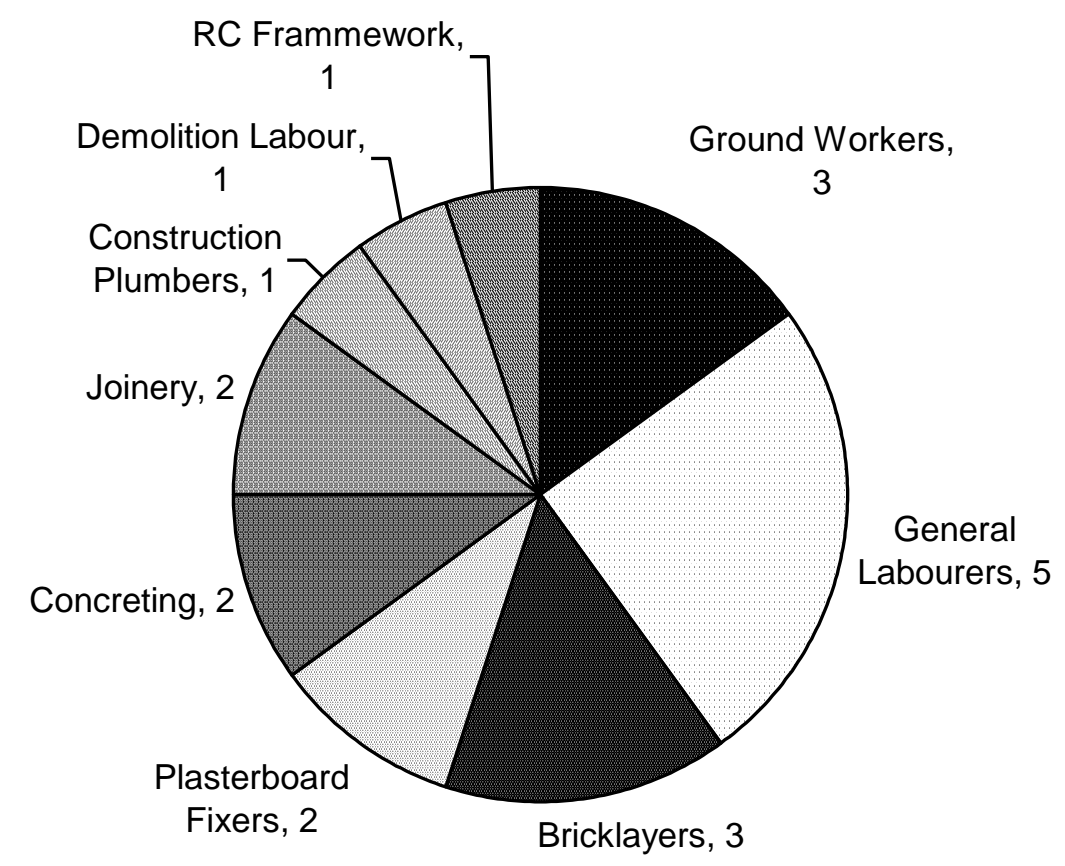

Figure 5 Responses to Telephone Survey Question 2

Question 3 - How do you ensure that these workers understand their health and safety responsibilities 


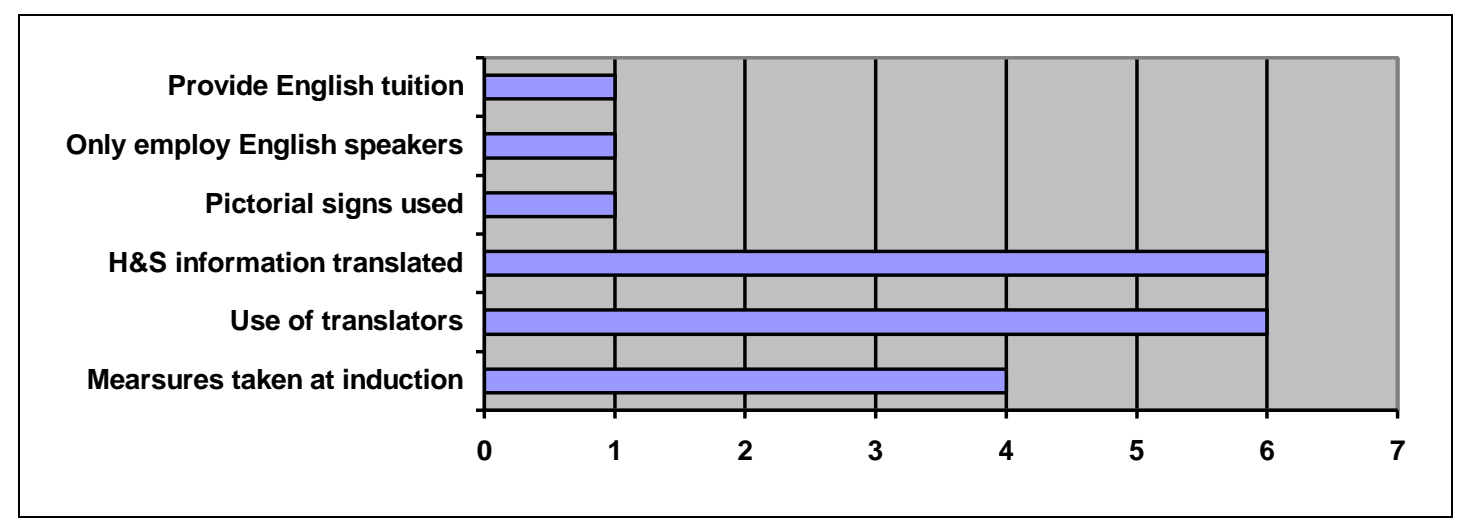

Figure 6 Responses to Telephone Survey Question 3

Question 4 - What, would you say, are the consequences to the management of health and safety in construction of employing migrant workers.

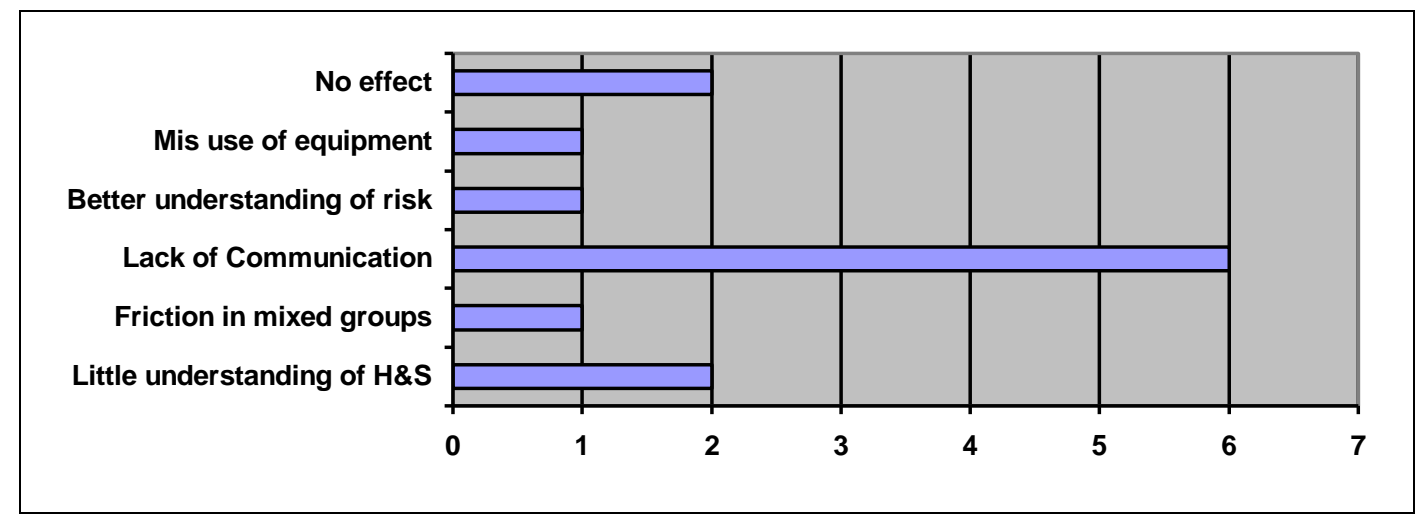

Figure 7 Responses to Telephone Survey Question 4

Question 5 - In the next ten years do you think the construction industry will use more, less or the same amount of migrant workers.

All of the respondents said that they expected that the UK construction industry would use more migrant workers in the next 10 years.

\subsection{Site Visit}

The Pilot study was focused on the following research question:

'What sorts of knowledge do construction workers use to inform their health and safety practices on site? To what extent are personal/cultural knowledge and priorities privileged over information supplied in (audio)visual health and safety materials'?

The study had four stages a) workers were video recorded working on site, b) the video was analysed to identify any health and safety hazards, c) video stills were taken from the sequence and printed off, d) the site's Health and Safety DVD was viewed by the researchers before going on site, e) we observed work on site, and f) three construction workers were interviewed off site in the canteen. Below we argue that in order to fill the gap in existing knowledge we identified above, 
systematic in-depth qualitative visual research is needed. We draw from the findings and implications of this pilot to demonstrate and support our argument.

\section{Discussion}

The research relating to construction safety and globalisation in developing countries has highlighted the aspects of the management process that require the provision of additional resources. Of these, it was felt that issues relating to language, literacy and the communication of health and safety information not only required further investigation but also resonated with issues relating to the use of migrant labour on UK and mainland Europe construction projects. The actions of some of the major stakeholders in the construction industry (Health and Safety Executive, Construction Industry Training Board and the Construction Confederation) in preparing guidance documents to assist construction companies to deal with language barriers also demonstrates how the increase in migrant workers in UK construction is a matter for concern.

In our initial investigations in the UK, health and safety managers often began by saying that migrant workers pose no additional risk and then explained a series of measures they take to ensure that they are properly aware of health and safety and inducted into site rules, practices and procedures.

Many UK construction companies indicate that gangs of migrant workers are permissible on site provided they are accompanied by someone who can translate information for them. Whilst translation of lay terms may be within the grasp of most interpreters, it is important that the personnel employed to do this are able to understand technical terms associated with the workings of the project. While the telephone survey results indicated that the use of translators and the translation of health and safety information (Figure 6) are the methods most likely to be used to manage migrant workers, lack of communication (Figure7) was seen as the main consequence of employing migrant workers.

As we have outlined above, in developing countries and in the UK, there is increasing use of, and recommendations for the use of (audio)visual media for communicating about health and safety in multicultural contexts. We have suggested that this method has great potential to improve communication and understanding about health and safety amongst construction workers. But as yet there is still insufficient understanding to ensure that audio(visual) communications work as they are intended to do. We need to know more about 1) how construction workers of different cultures understand health and safety themselves, and 2) how they use these understandings to interpret health and safety texts. We therefore propose that a full analysis of the limitations and potentials of the use of (audio)visual materials for health and safety communication both about and actually installed on construction sites is needed. This should include an analysis of the texts themselves, how they are produced and their content, and a study of how they are interpreted by their intended audiences of construction workers from different cultures. Such research should take the following stages:

1. An analysis of existing (audio)visual texts and their production: Following an initial survey of existing materials a representative sample of the different visual methods of communication that are currently being used internationally will be collected. They will be analysed following the visual cultural studies method for analysing visual images developed by Martin Lister and Liz Wells which 'allows the analyst to attend to the many moments within the cycle of production, circulation and consumption of the image through which meanings 
accumulate, slip and shift' (Lister and Wells 2000: 90). The designers of the texts will be interviewed to provide background information and any existing documentation about the design process, any research that was undertaken as part of this and what they hoped the texts would achieve. In order to determine the (culturally specific) conventions and discourses through which they are constructed and communicate the existing visual texts and exhibited forms/installations will be analysed and compared using visual content and discourse analysis methods (Rose, 2001).

2. An analysis of what the images mean to construction workers: From the first stage of the research we will be able to learn about how the texts are constructed, the types of narratives through which they communicate, the discourses they represent and how they are intended to communicate. However, in everyday practice the meanings of visual images are always context dependent (Pink, 2001; Banks, 2001; Rose, 2001). Visual meanings actually depend on 'who is looking', their culture and social class, and moreover may shift over time as people's perspectives change. In the context of the globalisation of construction work outlined earlier in this article the construction workers who view or interact with (audio)visual health and safety texts and installations will more often than not be from diverse cultural
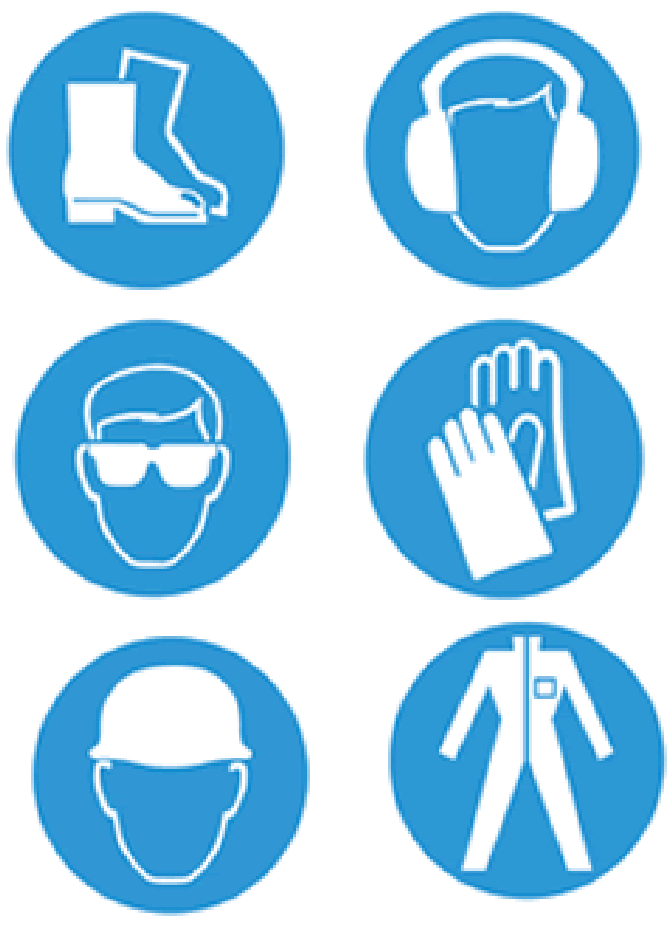

Figure 8 Mandatory PPE Signs

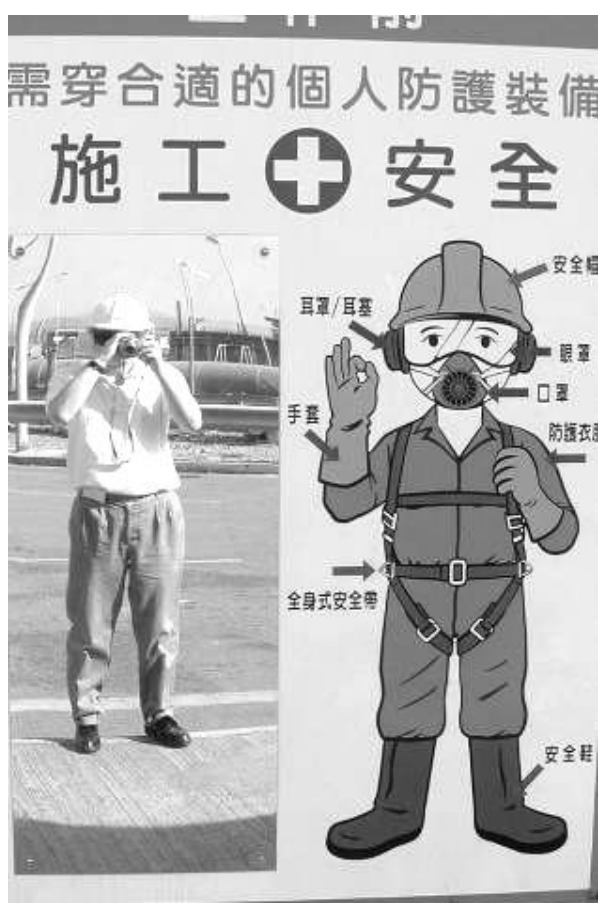

Figure 9 Safety installation Hong Kong

backgrounds and will frequently be migrant labourers working in situations where they have limited skills in the language of the host culture. Visual anthropological studies have shown that it is quite possible that people will use their own existing cultural and personal stereotypes to interpret the actions of people represented in documentary films, rather than on the terms of the message intended by the filmmaker.' Construction workers may use culturally specific knowledge to understand (audio)visual texts about health and safety and, like anyone else, might interpret them in terms of cultural narratives that are already familiar to them, rather than in terms of the meanings the author of the text intended. Our 
pilot study also implied that construction workers, many of whom have many years of experience of working on multiple sites, have their own experiencebased knowledge about their working environments and practices. They consider construction sites to be dangerous places and that health and safety are of utmost importance, but they also have their own views about how to ensure their own, and others', safety and what their priorities should be, along with their own corresponding definitions of what health and safety are. Indeed, our pilot suggested that most construction workers would not define 'health' and 'safety' in terms that correspond directly with the ways these categories are defined in official Health and Safety regulations. In this sense it is important to remember that given that they are the owners of this experience-based (rather than scientific) expertise they are also likely to be critical viewers of any audiovisual texts on construction sites and on-site work practices. With increasing ethnic and cultural diversity amongst construction workers, this problem is compounded in that critical readings of health and safety messages will be based on range of different sets of experience-based knowledge. To give one of the more extreme examples, as one of the health and safety managers interviewed put it: 'if they've come from a war zone its hard to get them to wear a hard hat'.

It is absolutely crucial that the first stage of research - an analysis of the (audio)visual texts and installations themselves - is followed by a qualitative study of how construction workers actually interpret and use (audio)visual texts and exhibits on site.

3. Recent research has demonstrated the effectiveness of using ethnographic applied visual anthropology methods for understanding how other people experience their everyday environments, and the values, motivations and knowledge that inform their actions and everyday practices (Pink 2004, 2005, 2007). Applied visual anthropologists then use this type of research knowledge to intervene in some way to improve the circumstances in which their research subjects live, and in some cases, work. Such methodologies have recently been developed in projects in contexts such as clinical health care (Chalfen and Rich 2007, Lammer 2007), disaster and crisis relief (Jhala 2007, Durington 2007), post-conflict recovery (Flores 2007), sustainable development (Stadhams 2007, Martinez Perez 2007) and, perhaps most relevant here, industry (Pink 2004, Sperschneider 2007).

Using such qualitative methods construction workers' interactions with and interpretations of selected existing visual images and installations intended to provide health and safety information, such as those shown in Figures 1, 2, 3, 8, and 9, and also DVDs, leaflets and other materials that are provided as part of the Heath and Safety induction process that workers are required to go through before going on site, will be investigated in two ways. Our pilot study has implied that the actual health and safely priorities and values of construction workers may vary from the priorities that have been developed on the basis of scientific knowledge and that are represented in health and safety regulations. This means that it is essential to recognise and identify these different understandings of what health and safety involve and the practices that these understandings engender. Therefore, this stage of the research will continue our investigation into the sorts of cultural and personal/experience-based knowledge upon which construction workers' own views on and definitions of health and safety are based. In the pilot study we used a method called 'photo-elicitation' (see Pink 2007, ch3) which involves asking interviewees to respond to photographs. It has been suggested that 'images evoke deeper elements of human consciousness than do words' and 'the photo elicitation interview seems like not simply an interview process that elicits more information but rather one that evokes a different kind of information' (Harper 2002: 13). We are particularly interested in 
the quality of information that can be generated through photo-elicitation because it provides us with an opportunity to access the forms of knowledge based on bodily experiences and memories that might be sparked off through the empathetic associations that can be produced when a research participant is viewing a photograph. By asking our interviewees to comment on a set of photographs of actual operations that they or their colleagues had been involved in the previous week we also provided them with visual images that had personal relevance to them, that offered them a basis from which to develop their own expert commentaries. The responses showed how experience-based and, what they called 'commonsense' knowledge based on their own previous practical experiences of working with others and their memories of previous injuries (which had often happened in the past before health and safety guidelines had been issued) informed some of their health and safety practices. However, although in this sense construction workers feel responsible for their own health and safety, other examples that were described to us implied that, in some ways, construction workers might feel they have little control over some aspects their own health and safety. For example, if a construction worker believed that some health problems associated with construction work, like a bad back, were inevitable and they had no influence on the matter. In addition, construction workers might sometimes find themselves in situations where they are tempted to risk their own safety in order to complete a job faster.

Data produced through photo-elicitation interviews about construction workers' approaches to health and safety and their own personal and cultural knowledge will form a vital part of our analysis of their everyday routine practices. Areas to be covered in the interviews will include: exploring the workers' cultural, personal and experiential knowledge about and understanding of health and safety; their uses of images/installations; exploration of the cultural and personal factors that inform how individual construction workers interpret images/installations; and asking them to explain aspects of their everyday health and safety practices as recorded on-site. However, to understand their actual practices we will add to the photo-elicitation data by using participatory collaborative research methods developed in applied visual anthropology. This will include using a phenomenological approach that seeks to understand how construction workers experience and understand the social and physical environments in which they work. Our pilot observations and interviews indicated that, in order to gain this in-depth knowledge, we would need to: accompany individual construction workers during their everyday working routines, using video or photography to record this as appropriate; ask them to show the researcher how to use health and safety texts him/herself (i.e. to give the researcher a sense of how it feels to use these texts site); and make video recordings of them using interactive visual 'check-point' type installations (e.g. such as the example shown in Figure 5). These methods are all adapted from similar video and photographic research methods that have been developed in applied visual anthropology studies. They draw particularly from the video tour method used by Pink (e.g. Pink 2004) and the 'design in context' video method used by Werner Sperschneider in his work as a Design Anthropologist for Danfoss in Denmark (Sperschneider 2007).

In an analysis of the recent Steps for the Future series of films produced in South Africa as part of an HIV/AIDS awareness campaign, the anthropologist Susan Levine discusses why this campaign has succeeded in connecting with its target audience. Levine's research included looking at how local people engaged with the film's content and how it became meaningful for them. She shows that these films for which 'scripts are drawn from life and acted by the characters themselves' as such use narratives that are both familiar and meaningful and for the people there are intended for, they: 'tell local stories in local languages about people living with HIV/AIDS' (Levine 2007). The programme of research we are 
proposing aims to achieve something similar by attending to the narratives, stories and everyday issues that are actually confronted by construction workers and the ways in which these interact with the ways that (audio)visual health and safety texts and installations are currently developing. We hope to be able to provide insights into how visual communications about construction sites might also tell stories that are sufficiently close to their experiences to communicate effectively about health and safety.

\section{On Going Research}

The multidisciplinary team at Loughborough University have continued to develop this area of research and in 2007 are carrying out two more extensive research projects, one on migrant construction workers and health and safety and the other, communication of health and safety messages in construction.

\section{Conclusions}

Construction is often the largest employer in any country. It is well documented that it is a hazardous industry where records of accidents are recorded and as such good management of health and safety can have a beneficial affect on countless individuals. The effects of Globalisation, budget air travel and improved communication and business practices through the internet have had a magnifying affect on political and legislative decisions on economies and labour. Health and safety mangers now have to deal with a flux of international workers and revise their procedures and tools to suit.

The use of migrant workers in UK construction appears to be on the increase with around $50 \%$ of the unskilled workforce being reported in some companies. They are being used in a wide variety of trades but mostly in general labour work. Health and safety managers are identifying workers who have difficulty understanding English at the induction stage and insist that sub contractors provide English speakers to be present in gangs of foreign workers. Much of the existing health and safety documentation and signs are being translated into the many different languages.

In this context we argue that it is crucial to identify the sorts of (audio)visual narratives and forms that can effectively communicate about Health and Safety in ways that are meaningful and relevant to construction workers employed in multicultural contexts. We suggest that it is by gaining an understanding of the experiential knowledge and cultural narratives that construction workers use to inform their understandings of health and safety, that this can be achieved.

Other organisations in the UK have carried out research into migrant workers in the UK (HSE 2006) or in the process of looking at migrant worker flow and how this will affect the construction industry (Construction Industry Training Board) but the proposed research detailed above looks specifically at health and safety in construction and it is intended that any resulting tools or guidance will have application internationally

\section{REFERENCES}

Balch, A. and Geddes, A. (2003) UK migration policy in light of sectoral dynamics: the case of the construction sector. Unpublished research.

Banks, M. (2001) Visual Methods in Social Research, London: Sage. 
Bust, P.D. and Gibb, A.G. (2006) Construction Health and Safety in Developing Countries. European Construction Institute. UK.

Chalfen, R. and M. Rich (2007) 'Combining the applied, the visual and the medical: patients teaching physicians with visual narratives' in S. Pink (ed) Visual Interventions, Oxford: Berghahn

Delp, C. and Jones, J. (1996) Communicating information to patients: the use of cartoon illustrations to improve comprehension of insructions. Academic Emergency Medicine, 3(3), pp. 264-270.

Durington, M. (2007) 'The Hunters Redux: applied participatory visual strategies among the Botswana !Xo' in S. Pink (ed) Visual Interventions, Oxford: Berghahn

Flores, C. (2007) 'Indigenous Video, Development and Shared Anthropology: a collaborative experience with Maya-Q'eqchi' film-makers in post-war Guatemala' in S. Pink (ed) Visual Interventions, Oxford: Berghahn

Haslam, R.A., Hide, S.A., Gibb, A.G.F., Gyi, D.E., Pavitt, T., Atkinson, S., Duff, A.R. (2005) Contributing Factors in Construction Accidents, Applied Ergonomics 36 401-416.

Harper, D. (2002). 'Talking about pictures: A case for photo-elicitation' Visual Studies, 17(1), 13-26

HSE (2003) Acting on responses to HSE's Discussion Document: Revitalising Health and Safety in Construction.

HSE (2006) Migrant workers in England and Wales An assessment of migrant worker health and safety risk.

Jhala, J. (2007) 'Emergency Agents: a birthing of incipient applied visual anthropology in the 'media invisible' villages of Western India.' in S. Pink (ed) Visual Interventions, Oxford: Berghahn

Kartam, N.A., Flood, I. And Koushki, P. (2000) Construction Safety in Kuwait: issues, procedures, problems, and recommendations. Safety Science 36163184.

Lammer, C. (2007) 'Bodywork: social somatic interventions in the operating theatres of invasive radiology' in S. Pink (ed) Visual Interventions, Oxford: Berghahn

Langford, D. (2000) The Influence of Culture on Internationalisation of Construction. In Construction in Developing Countries,. 15 - 17 November, Gabarone, Botswana.

Leiner, M., Handal, G. and Williams, D. (2004) Patient communication: a multidisciplinary approach using animated cartoons. Health education research, 19, pp. 591-595.

Levine, S. (2007) 'Steps For the Future: HIV/AIDS, media activism, and applied visual anthropology in Southern Africa' in S. Pink (ed) Visual Interventions, Oxford: Berghahn

Lister, M. and Wells, L. (2000) 'Seeing beyond belief: Cultural studies as an approach to analysing the visual' in T. van Leeuwen and C. Jewitt (eds) The Handbook of Visual Analysis, London: Sage.

MacDougall, D. (1998) Transcultural Cinema, Princeton: Princeton University Press.

Martinez, W. (1996) 'Deconstructing the "viewer": from ethnography of the visual to critique of the occult', in P.I. Crawford S.B. Hafsteinnson (eds), The Construction of the Viewer. Aarhaus: Intervention Press.

Martinez Perez, A. (2007) 'The rhythm of our dreams: a proposal for an applied visual anthropology' in S. Pink (ed) Visual Interventions, Oxford: Berghahn

Oller, J.W. and Giardetti, J.R. (1999) Images That Work; Creating Successful Messages in Marketing and High Stakes Communication. Westport, СT06881: Greenwood Publishing Group Inc.

Pink, S. (2004) Home Truths, Oxford: Berg

Pink, S. (2005) The Future of Visual Anthropology, London: Routledge

Pink, S. (2007 [2001]) Doing Visual Ethnography, London: Sage 
Racicot, B.M. and Wogalter, M.S. (1995) Effects of a video warning sign and social modelling on behavioural compliance. Accident Analysis \& Prevention, 27(1), pp. 57-64.

Rose, G. (2001) Visual Methodologies, London: Sage

Schellekens, P. and Smith, J. (2004) Language in the construction industry: Communicating with second language speakers Report for CITB-Construction Skills

Sherwin, R. K., N. Feigenson and C. Spiesel (forthcoming) 'What is visual knowledge and what is it good for?: Potential ethnographic lessons from the field of legal practice' in Visual Anthropology

Sperschneider, W. (2007) 'Video Ethnography under Industrial Constraints observational techniques and video analysis' in S. Pink (ed) Visual Interventions, Oxford: Berghahn

Stadhams, D. (2007) 'Look To Learn: a role for visual ethnography in the elimination of poverty' in S. Pink (ed) Visual Interventions, Oxford: Berghahn

Torrance, J.V.B. (2004) Globalisation And Trends In The International Construction Industry: A Malaysian Perspective In Proceedings of the International Conference on Globalisation and Construction: Meeting the Challenges and Reaping the Benefits, 17-19 November, Bangkok.

\footnotetext{
'E.g. Wilton Martinez (1996) found this when researching how US university students interpreted documentary films about other cultures.
} 